\title{
Expression of Human Immunodeficiency Virus Type 1 Neutralizing Antibody Fragments Using Human Vaginal Lactobacillus
}

\author{
Angela Marcobal, ${ }^{1}$ Xiaowen Liu, Wenlei Zhang, ${ }^{2}$ Antony S. Dimitrov, Letong Jia,, Peter P. Lee, \\ Timothy R. Fouts, Thomas P. Parks, and Laurel A. Lagenaur ${ }^{1}$
}

\begin{abstract}
Eradication of human immunodeficiency virus type 1 (HIV-1) by vaccination with epitopes that produce broadly neutralizing antibodies is the ultimate goal for HIV prevention. However, generating appropriate immune responses has proven difficult. Expression of broadly neutralizing antibodies by vaginal colonizing lactobacilli provides an approach to passively target these antibodies to the mucosa. We tested the feasibility of expressing single-chain and single-domain antibodies (dAbs) in Lactobacillus to be used as a topical microbicide/live biotherapeutic. Lactobacilli provide an excellent platform to express anti-HIV proteins. Broadly neutralizing antibodies have been identified against epitopes on the HIV-1 envelope and have been made into active antibody fragments. We tested single-chain variable fragment $\mathrm{m} 9$ and $\mathrm{dAb}-\mathrm{m} 36$ and its derivative $\mathrm{m} 36.4$ as prototype antibodies. We cloned and expressed the antibody fragments $\mathrm{m} 9, \mathrm{~m} 36$, and $\mathrm{m} 36.4$ in Lactobacillus jensenii-1153 and tested the expression levels and functionality. We made a recombinant L. jensenii 1153-1128 that expresses dAb-m36.4. All antibody fragments $\mathrm{m} 9, \mathrm{~m} 36$, and $\mathrm{m} 36.4$ were expressed by lactobacilli. However, we noted the smaller m36/m36.4 were expressed to higher levels, $\geq 3 \mu \mathrm{g} / \mathrm{ml}$. All L. jensenii-expressed antibody fragments bound to gp120/CD4 complex; Lactobacillus-produced m36.4 inhibited HIV-1 $1_{\mathrm{BaL}}$ in a neutralization assay. Using a TZM-bl assay, we characterized the breadth of neutralization of the m36.4. Delivery of dAbs by Lactobacillus could provide passive transfer of these antibodies to the mucosa and longevity at the site of HIV-1 transmission.
\end{abstract}

Keywords: HIV neutralization, single-domain antibody, Lactobacillus, passive delivery

\section{Introduction}

$\mathbf{N}$ EUTRALIZING ANTIBODIES WERE among the first inhibitors identified against human immunodeficiency virus type 1 (HIV-1) infections. Active immunization to generate an appropriate de novo HIV neutralizing antibody response remains the ultimate goal but has proved challenging. ${ }^{1}$ Passive topical delivery of antiviral antibodies at or on mucosal surfaces, in the vaginal and cervix, can interrupt the cycle of virus infection ${ }^{2-6}$; however, obtaining and maintaining effective levels of such antiviral antibodies can be costly and short lived.

Thus, new strategies are needed for providing neutralizing antibodies at the mucus surface where HIV is transmitted. One innovative avenue is to use a recombinant commensal Lacto- bacillus as a vehicle for releasing neutralizing antibodies at the mucosa. Lactobacillus species are common members of the vaginal microbiota in healthy women of childbearing age $e^{7,8}$ and interact with the host to reduce proinflammatory cytokine levels and serve as the major host inflammatory modulator. ${ }^{9}$ Lactobacillus jensenii is one of the more predominant vaginal lactobacilli. The strain $L$. jensenii 1153 has been proven as a potential platform to deliver sufficient levels of the anti-HIV protein-modified cyanovirin- $\mathrm{N}$ to mucosal surfaces to protect macaques from Simian (S)HIV challenge. ${ }^{10}$

HIV-1 entry into target cells requires the sequential binding of the viral envelope glycoprotein gp120 epitopes to CD4 and then to the CCR5 chemokine receptor. ${ }^{11}$ When CD4 binds to the HIV envelope, a conformation change in gp120 exposes the cryptic epitopes known as the CD4-induced

\footnotetext{
${ }^{1}$ Osel, Inc., Mountain View, California.

${ }^{2}$ Profectus Biosciences, Inc., Baltimore, Maryland.
}

(C) Angela Marcobal et al., 2016; Published by Mary Ann Liebert, Inc. This Open Access article is distributed under the terms of the Creative Commons Attribution Noncommercial License (http://creativecommons.org/licenses/by-nc/4.0/) which permits any noncommercial use, distribution, and reproduction in any medium, provided the original author(s) and the source are credited. 
(CD4i) site. ${ }^{12,13}$ When a CD4i antibody is present, it recognizes these previously unexposed sites, blocking virus attachment of HIV to the chemokine receptor. ${ }^{14}$

Different variants of anti-HIV antibodies have been developed, such as single-chain variable fragments (scFvs), small antibody fragments, and even smaller domain antibodies (dAbs). These alternatives offer advantages over conventional antibodies because of their smaller size, robustness, and their ability to be expressed in bacteria. Moreover, the small size of the dAbs and scFvs overcomes the steric constraints when the virion is bound to CD4; an intact IgG molecule may not be able to access the CD4i bridging sheet. ${ }^{15}$ Numerous scFvs and dAb variants and camel-derived antibodies have now been identified that retain the broadly neutralizing anti-HIV activity. ${ }^{16-22}$ Among these broadly neutralizing antibody fragments are ScFv-m9, ${ }^{23,24}$ dAb-m36, ${ }^{25,26}$ and dAb-36.4 variant ${ }^{19}$ that bind CD4i regions and facilitate neutralization of a broad range of HIV isolates.

We selected these antibody fragments that target the highly conserved CD4i epitopes, for expression in Lactobacillus as entry inhibitors, since they are likely to be present across the wide genetic diversity of HIV-1 variants. In addition, their small size may put less strain on the recombinant Lactobacillus allowing for expression levels that are biologically relevant.

In this article, we optimized and compared the expression of scFV-m9, dAb-m36, and dAb-m36.4 by L. jensenii. We evaluated the breadth and potency of dAb-m36.4 against different HIV-1 subtypes. Finally, we constructed a recombinant L. jensenii 1153-1128 producing dAb AP-m36.4.

\section{Materials and Methods}

Bacterial strains, culture, plasmid construction, and transformation

L. jensenii strain 1153, a vaginal isolate from a healthy woman, was cultivated as described previously. ${ }^{27}$ To express $\mathrm{m} 9$ or $\mathrm{m} 36$ antibody fragments in L. jensenii 1153 , the $m 9$ or $m 36$ genes were cloned into the modular shuttle vector pOSEL175, a modified version of pOSEL144. ${ }^{27}$ The expression cassette for secreted scFv-m9 or dAb-m36 contained the Lactococcus promoter p23, the signal sequence from the ribosome binding site to the signal peptidase cleavage site of the $L$. crispatus $\mathrm{S}$-layer gene (CbsAss) (for protein secretion), and a C-terminal epitope tag DYKDDDDK (FLAG) with a TAA stop codon at the $3^{\prime}$ end.

For purification ease, Profectus Biosciences Inc. modified the cassettes for the $m 9, m 36$, and $m 36.4$ genes to include a Cterminal albumin-binding domain (ABD), SA06 for improving its pharmacokinetic properties and also aiding in purification using rat serum albumin (RSA) columns. ${ }^{28}$ The original $m 9$ and $m 36$ genes do not bind albumin. The OSEL shuttle plasmids were maintained and propagated in Escherichia coli, purified, and electroporated into L. jensenii 1153 as described before, ${ }^{27}$ generating the transformed strains L. jensenii 1153-1126p (expressing m9), L. jensenii 1153-1127p (expressing m36), and L. jensenii 1153-1128p (expressing m36.4). Transformed lactobacilli were routinely propagated using Man Rogosa Sharpe (MRS) or Rogosa media (broth or agar) with $20 \mu \mathrm{g} / \mathrm{ml}$ of erythromycin. $L$. jensenii 1153-1128 was propagated on MRS or Rogosa broth or agar without antibiotic.

\section{Western blots}

Stationary-phase supernatants from transformed (plasmid expressed) L. jensenii 1153-1126p, L. jensenii 1153-1127p, and L. jensenii 1153-1128p were harvested and centrifuged to remove cell debris. Thirty microliters of supernatant was run on a $12 \%$ Bis-Tris Gel (Life Technologies) and transferred to polyvinylidene difluoride membranes using an iBlot (Life Technologies). The $\mathrm{m} 9, \mathrm{~m} 36$, or AP-m36.4 proteins were detected using monoclonal mouse anti-FLAG antibody (Pierce Thermo) dilutes 1:1,000 and the anti-mouse Western Breeze Chemiluminescent Kit (Life Technologies).

\section{Purification and bioactivity characterizations of Lactobacillus-derived m36.4}

The L. jensenii strains expressing $\mathrm{m} 9$ and $\mathrm{m} 36$ (each containing the ABD) from plasmids were cultured in Rogosa SL broth (Difco) to stationary phase. Cell-free supernatants were centrifuged, filtered, and purified using the (i) albumin Sepharose column (RSA bound to cyanogen bromide [CNBr]-activated Sepharose 4B; GE Healthcare) or (ii) fulllength single-chain (FLSC) column (gp120/CD4 complex bound to $\mathrm{CNBr}$-activated Sepharose $4 \mathrm{~B}$ ). In both methods, the columns were equilibrated with phosphate-buffered saline (PBS), the supernatant supplemented with $0.5 \mathrm{M}$ sodium chloride $(\mathrm{NaCl})$ passed slowly through the column to ensure at least 1 min of contact time, column washed with at least 20 bed volumes PBS supplemented with $0.5 \mathrm{M} \mathrm{NaCl}$ and $\mathrm{m} 36$ eluted with $0.2 \mathrm{~N}$ citric acid, $\mathrm{pH} 3.0$.

The eluant was immediately neutralized to $\mathrm{pH}$ 6.0-8.0 using $1 \mathrm{M}$ Tris at pH 9.0 and dialyzed against PBS. Control $E$. coli expressed $\mathrm{m} 36.4$ was purified by sequential ion exchange column (Q HP Sepharose Fast Flow columns; GE Healthcare Life Sciences) and size exclusion column (Superdex 75 column, $120 \mathrm{ml}$ bed volume; GE Healthcare). Periplasmic extract from HB2151 expressing m36.4 was dialyzed against $20 \mathrm{mM}$ piperazine, $\mathrm{pH} 5.8$, centrifuged at $14,000 \mathrm{~g}$ for $30 \mathrm{~min}$, and loaded onto the Q HP column. The column was washed with $20 \mathrm{mM}$ piperazine, $0.15 \mathrm{M} \mathrm{NaCl}, \mathrm{pH} 5.8$ buffer, and the bound protein eluted using gradient salt elution from 0.15 to $0.50 \mathrm{M} \mathrm{NaCl}$. M36 and $\mathrm{m} 36.4$ eluted in the peak in the range of $0.2 \mathrm{M} \mathrm{NaCl}$. The collected eluant from this peak was passed through a size exclusion column to eliminate the majority of high-molecular weight contaminants.

Preparations of $\mathrm{m} 9, \mathrm{~m} 36$, and $\mathrm{m} 36.4$ were quantified by Coomassie blue staining and gp120/CD4 capture enzymelinked immunosorbent assay (ELISA). FLSC (CD4-gp120) leached from column was removed by an additional passage over an RSA column. The amount of RSA leached from the column was insignificant.

Although LPS levels were not measured following purification from $E$. coli, similar antibody fragments purified previously had $<10 \mathrm{EU} / \mathrm{mg}$ of protein.

\section{Gp120/CD4 binding (capture ELISA)}

A sheep antibody, D7324 (Aalto Bio Reagents), which binds to a motif (amino acid 497-511) in the envelope gene gp120, was coated on ELISA plates at $2^{\circ} \mathrm{C}-8^{\circ} \mathrm{C}$, at a concentration of $2 \mu \mathrm{g} / \mathrm{ml}$, overnight. Plates were then washed with Tris-buffered saline with Tween (TBST) and blocked with 5\% skim milk. FLSC (a gp120/CD4 complex), at a 
concentration of $0.2 \mu \mathrm{g} / \mathrm{ml}$ in PBS, was captured on D7324 and the plate was washed with TBST. Titrated samples of $\mathrm{m} 9, \mathrm{~m} 36$, and $\mathrm{m} 36.4$ solution were overlaid onto the FLSC, incubated for $1 \mathrm{~h}$, and washed with TBST. All antibody fragments bound to FLSC and were detected using the horseradish peroxidase (HRP)-conjugated mouse anti-FLAG antibody (clone M2; Sigma).

\section{Peripheral blood mononuclear cell neutralization assay (p24 assay)}

Human peripheral blood mononuclear cells (PBMCs) were purchased from SeraCare Life Sciences, Inc. HIV-1 $1_{B a L}$ virus was initially received from the NIH AIDS Reagents Program and later grown by Profectus Biosciences for laboratory use. PBMCs were infected with $\mathrm{HIV}-1_{\mathrm{BaL}}$ at a multiplicity of infection of 0.01 in the presence of $\mathrm{m} 36.4$ (purified as described above) with desired concentrations. The mixture was incubated at $37^{\circ} \mathrm{C}$ for 1 week, and the supernatant was lysed using 1\% Triton X-100 and quantified for p24 presence by using a p24 capture ELISA developed at Profectus BioSciences, Inc. Plates were coated with $3 \mu \mathrm{g} / \mathrm{ml}$ mouse monoclonal anti-p24 antibody (clone $39 / 6.14$ by ZeptoMetrix) washed with TBST, blocked with $5 \%$ casein and $4 \%$ rabbit serum, washed with TBST, overlaid with the lysed p24 containing supernatant, incubated for $1 \mathrm{~h}$, and washed with TBST. Bound p24 was detected using the HRP-conjugated rabbit polyclonal anti-p24 antibody (1303-P; ImmunoDX, LLC).

\section{Construction of recombinant $\mathrm{L}$. jensenii 1153-1128}

Before insertion of the antibody cassette into the Lactobacillus chromosome, two modifications were made. The two-amino-acid peptide (AP), corresponding to the $\mathrm{N}$ terminus of the mature CbsA protein, was inserted downstream of the CbsA signal sequence at the N-terminus of the m36 protein to more closely resemble the native signal peptidase cleavage site of this protein. A point mutation at amino acid 44 glutamine (Q) to glutamic acid (E) Q44E was substituted for the original sequence. ${ }^{19}$ This point mutation, also called $\mathrm{m} 36.4$, confers greater breadth against HIV-1. The $A P$ m36.4 gene was cloned into Osel's integration vector.

For stable expression of AP-m36.4 in Lactobacillus, the AP$m 36.4$ gene expression cassette was integrated in single copy into the L. jensenii 1153 genome by homologous recombination into the minor capsid gene. The recombinant strain was selected by replicate plating into MRS agar with and without erythromycin. During successful integration, resolution of the plasmid occurs, which removes the erythromycin resistance gene. The integrated and resolved strain L. jensenii 1153-1128 contains a single copy of $A P-m 36.4$ gene and requires no antibiotic selection. The recombinant strain $L$. jensenii 1153 1128 was maintained in the MRS broth.

\section{TZM-bl neutralization assay}

The TZM-bl neutralization assay was used to evaluate antibody breadth and potency of $\mathrm{m} 36.4 .^{29}$ Neutralization experiments are expressed as $\mathrm{IC}_{50}$ titer of the protein in $\mu \mathrm{g} / \mathrm{ml} . \mathrm{m} 9$ and $\mathrm{m} 36$ were not tested.

\section{Results}

\section{Expression of antibody fragments in $\mathrm{L}$. jensenii}

We tested the feasibility of expressing anti-HIV-1 antibody fragments using a human vaginal Lactobacillus expression platform to produce a recombinant live biotherapeutic against HIV-1. We examined the scFv-m $9^{23,24}$ and single dAb-m36 (CD4i epitope $)^{25,26}$ and its derivative $\mathrm{m} 36.4 .{ }^{19}$ We cloned the $m 9$ and $m 36$ genes, which contained an ABD for purification ${ }^{28}$ and FLAG tag (for easy detection) into Osel's Lactobacillus expression vector p175 under the p23 promoter and transformed $L$. jensenii 1153 . A diagram of the plasmid construction of pOSELp23- $m 9$ and pOSELp23-m36 is shown (Fig. 1A). Supernatants from L. jensenii secreting $\mathrm{m} 9$ or m36 are detected by using an anti-Flag antibody and
A

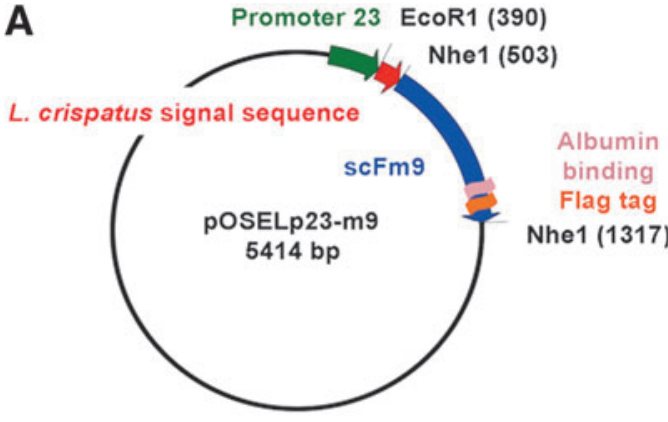

B

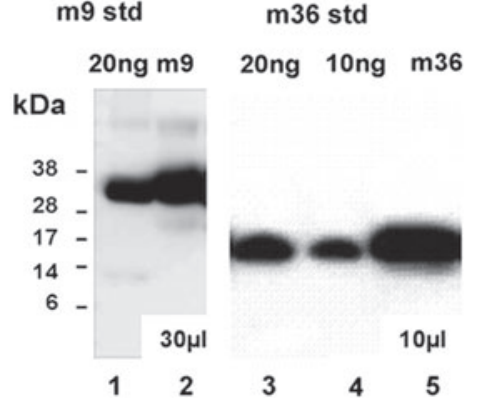

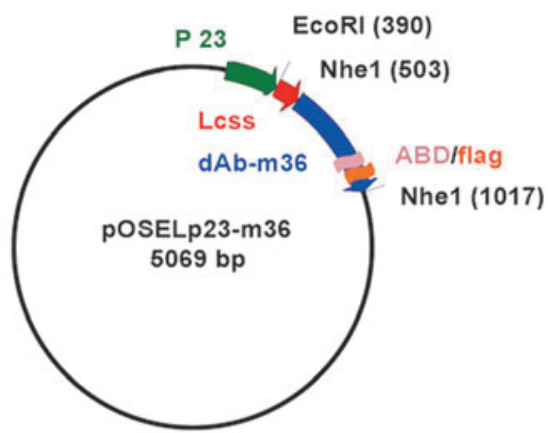

FIG. 1. Plasmids used in this study and protein expression. (A) Expression plasmids for scFv- $m 9$ and $\mathrm{dAb}-m 36$ are shown. Plasmids contain promoter P23 (green), Lcss (red), antibody fragment (blue), ABD (pink), and Flag epitope (orange). (B) Proteins and standards were run on $12 \%$-Bis-Tris gels, transferred to PVDF membrane, and visualized with anti-FLAG antisera. Lane 1, m9 standard $20 \mathrm{ng}$, Lane 2, Lactobacillus jensenii expressed $\mathrm{m} 9$ (30 $\mu$ l loaded), Lane 3, m36 standard $20 \mathrm{ng}$, Lane 4, m36 standard $10 \mathrm{ng}$, Lane 5, L. jensenii expressed m36 (10 $\mu \mathrm{l}$ loaded). ABD, albuminbinding domain; $\mathrm{dAb}$, domain antibody; Lcss, L. crispatus signal sequence; PVDF, polyvinylidene difluoride; $\mathrm{scFv}$, single-chain variable fragment. 
compared with a purified protein standard produced in $E$. coli (Fig. 1B). The estimated concentrations of $\mathrm{m} 9$ and $\mathrm{m} 36$ secreted were $\sim 660$ and $4.0 \mu \mathrm{g} / \mathrm{ml}$, respectively.

\section{Binding of antibody fragments to FLSC}

Supernatants of scFv-m9 and m36 expressed from plasmids transformed into L. jensenii 1153 were purified and tested for functionality by determining binding to FLSC (Fig. 2A, B). The scFv-m9 plasmid expressed by L. jensenii or scFv-m9 expressed by $E$. coli bound to the gp120-CD4 complex in ELISA, while the control supernatant from $L$.
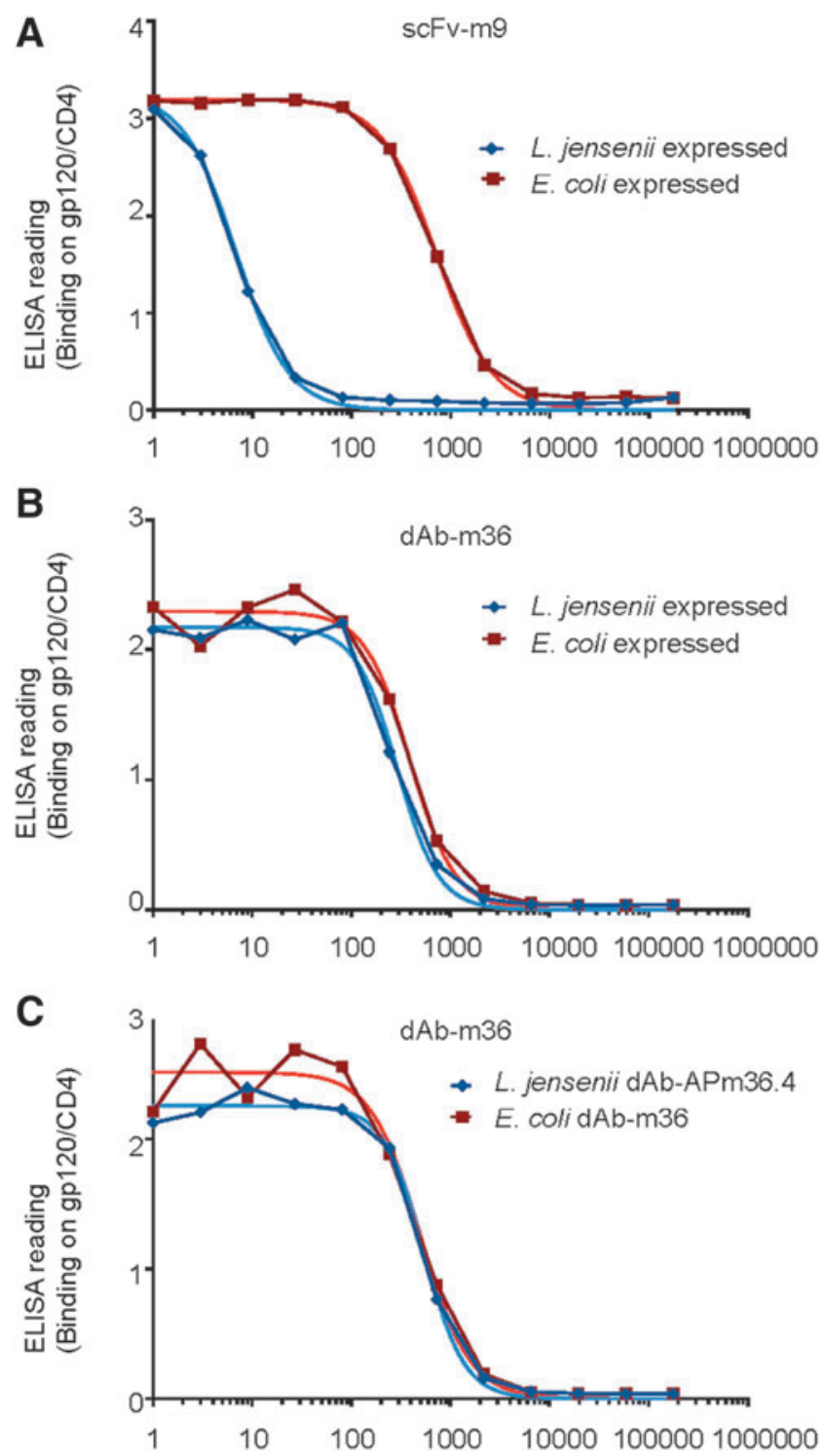

FIG. 2. ELISA readout of binding of antibody fragments to FLSC (gp120/CD4) and purity of m36.4 and AP-m36.4. Comparison of binding properties from antibody fragments produced by L. jensenii (blue) to Escherichia coli produced standards (red). (A) scFv-m9; produced from plasmid (B) dAb-m36; produced from plasmid (C) dAb-m36.4 (E. coli) versus dAb-AP-m36.4 (recombinant L. jensenii 1153-1128). Alanine proline N-terminal m36.4 (AP-m36.4). ELISA, enzyme-linked immunosorbent assay; FLSC, full-length single chain. jensenii did not (data not shown); however, scFv-m9 expressed by L. jensenii bound with lower affinity (Fig. 2A). Due to lower expression levels and lower affinity, scFv-m9 was not pursued further.

L. jensenii plasmid-expressed $\mathrm{m} 36$ bound to FLSC to the same level as the standard (Fig. 2B). The recombinant $L$. jensenii 1153-1128 expressed a modified version of m36.4, with the addition of amino acids alanine $(\mathrm{A})$ and proline $(\mathrm{P})$ at the amino terminus. Addition of the AP-sequence was previously shown to improve the secretion of full-length protein from L. jensenii. ${ }^{30}$ Both E. coli-expressed m36.4 and recombinant L. jensenii 1153-1128-expressed AP-m36.4 were tested to confirm that the addition of AP to the amino terminus of $\mathrm{m} 36.4$ did not influence binding to FLSC (Fig. 2C). The $\mathrm{EC}_{50} \mathrm{~s}$ were comparable: $E$. coli produced dAb-m36.4 $12.7 \mathrm{ng} / \mathrm{ml}$ and recombinant L. jensenii $1153-1128$ produced AP-m36.4 $11.9 \mathrm{ng} / \mathrm{ml}$ (no statistical difference).

\section{Antiviral activity of $m 36.4$}

L. jensenii-expressed m36.4 was purified using two techniques; purity of the protein using the different strategies is shown in Figure 3A. Purified m36.4 was tested for anti-HIV activity using a p24-PBMC-based assay (Fig. 3B). Both RSA-purified m36.4 and FLSC-purified m36.4 showed similar reduction of $\mathrm{p} 24$, and thus, the Lactobacillusproduced $\mathrm{m} 36.4$ protein was active against $\mathrm{HIV}_{\mathrm{BaL}}$ with an $\mathrm{IC}_{50}$ of $\sim 1 \mu \mathrm{g} / \mathrm{ml}$.

\section{Neutralization breadth of $m 36.4$}

Table 1 details the breadth of neutralization of the $\mathrm{m} 36.4$ protein. m36.4 was purified from $E$. coli and tested for activity against a panel of 68 pseudoviruses from each of the major genetic subtypes representing clades A, B, C, D, G, including transmitted founders $(\mathrm{T} / \mathrm{F})$ and circulating recombinant forms CRF01 AE and CRF02 AG. Table 1 shows the broadly neutralizing activity of $\mathrm{m} 36.4$ against clades $\mathrm{B}, \mathrm{C}$, and $\mathrm{D}$; most $\mathrm{IC}_{50}$ values were in the $\leq 5 \mu \mathrm{g} / \mathrm{ml}$. Less or no activity was noted against clades A, G, and CRFs. Previously, we tested a partially purified supernatant from wild-type L. jensenii in pseudovirus assays with $\mathrm{HIV}-1_{\mathrm{HxB} 2}$ envelope and found no inhibition. ${ }^{27}$ In addition, m36.4 did not inhibit MuLV control in the TZM-bl assay.

\section{Construct integration vectors and integrated single domain expression cassettes into the L. jensenii 1153 chromosome and tested phenotypic stability}

We constructed a recombinant $L$. jensenii 1153 by integrating an optimized AP-m36.4 antibody expression cassette into the minor capsid gene of L. jensenii 1153 through homologous recombination (Fig. 4A). The strains generated were evaluated for complete resolution of the plasmid and antibody production (not shown). A diagram of the two sets of internal and external primers, which were used to amplify the integration region within the minor capsid gene, is shown (Fig. 4B).

Polymerase chain reaction (PCR)-amplified genomic DNA from the parental L. jensenii 1153 and recombinant strain designated L. jensenii $1153-1128$ were run on a $2 \%$ agarose gel. L. jensenii 1153 shows a 353 bp band corresponding to a region of the minor capsid gene and a 1,824 bp band of the entire minor capsid gene (Fig. 4B). L. jensenii 


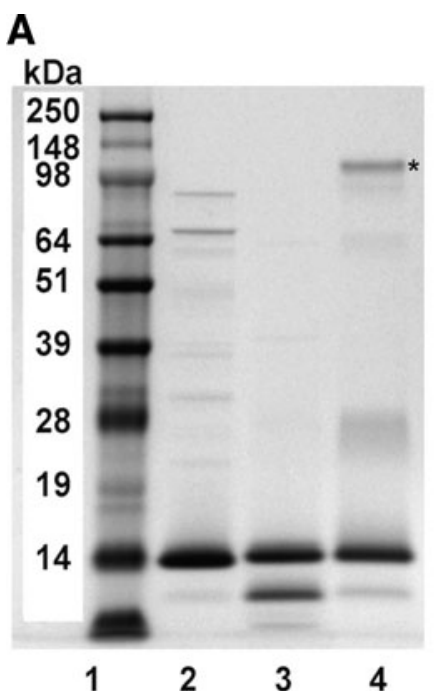

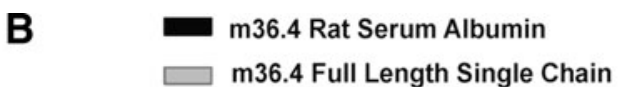

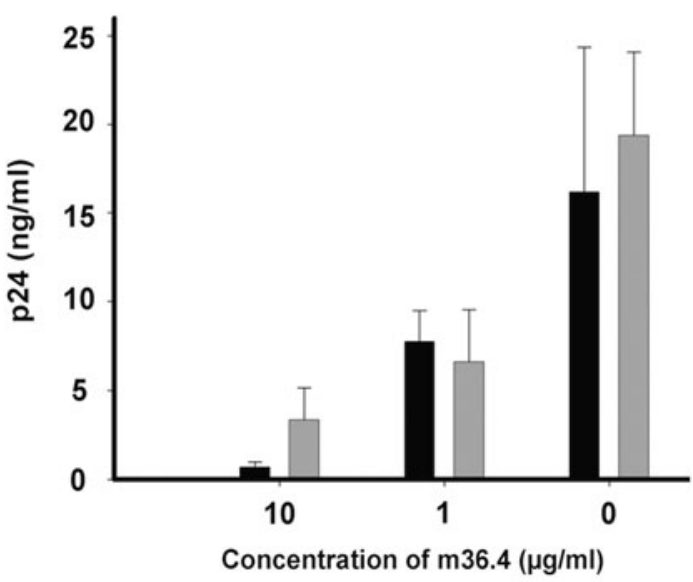

FIG. 3. Purification of AP-m 36.4 protein used for HIV inhibition assay. (A) Lane 1: see Blue Plus Prestained ladder (Invitrogen), Lane 2: $\mathrm{m} 36.4$ E. coli, $3 \mu \mathrm{g}$ (purified on Q, HP, sizeexclusion columns), Lane 3: L. jensenii 1153-1128 expressed AP-m36.4, $3 \mu \mathrm{g}$ (purified on RSA column), Lane 4: L. jensenii 1153-1128 expressed AP-m36.4, $7.4 \mu \mathrm{g}$ total protein (purified on FLSC column) * FLSC (CD4gp120) leached from column was removed by RSA. (B) AP-m36 produced by recombinant $L$. jensenii 1153-1128 inhibits $\mathrm{HIV}_{\mathrm{BaL}}$. Bar graph showing the p24 value measured. Each value is average of four replicates. $\mathrm{IC}_{50}$ for $\mathrm{AP}-\mathrm{m} 36.4$ produced in Lactobacillus is $\sim 1 \mu \mathrm{g} / \mathrm{ml}$. RSA, rat serum albumin.
1153-1128 shows a $1,250 \mathrm{bp}$ band corresponding to a region of the minor capsid gene with the $891 \mathrm{bp}$ band ( $+6 \mathrm{bp}$ restriction site) cassette insertion. The external primers amplify a 2,721 bp band $(1,824+891+6 b p)$.

The strain was passaged 40 generations, genomic DNA was extracted, and the cassette was sequenced (not shown). The 40-generation sample was also analyzed by PCR for stability. No changes were noted in the size of the internal and external primer bands 891 and 2,721, respectively, and thus, the L. jensenii 1153-1128 recombinant is genotypically stable. We examined phenotypic stability by performing a carbohy- drate utilization profile of parental strain L. jensenii 1153 . Both L. jensenii 1153 and L. jensenii 1153-1128 fermented glucose, D-fructose, D-mannose, $N$-acetylglucosamine, amygdalin, arbutin, wells, salicin, D-cellobiose, D-maltose, Dsaccharose, amidon (starch), and gentiobiose wells and hydrolyze esculin ferric citrate (data not show).

We tested growth of the 1153-1128 strain and lactic acid production $(\mathrm{pH})$ and compared them to parental strain L. jensenii 1153. L. jensenii 1153-1128 grew to the same level as the parental strain and reduced $\mathrm{pH}$ of the media under aerobic $(5 \%$ $\mathrm{CO}_{2}$ ) and anaerobic growth conditions (Fig. 4C, D).

TABle $1 . \mathrm{IC}_{50}$ Titer M36.4 IN TZM-BL Cells ( $\left.\mu \mathrm{G} / \mathrm{ML}\right)$

\begin{tabular}{|c|c|c|c|c|c|}
\hline $\mathrm{A}$ & & $\mathrm{BC}$ & & CRF01-AE & \\
\hline Q461.e2 & 3.433 & CNE19 & 0.446 & $620345 . c 01$ & $>20$ \\
\hline Q769.d22 & 2.759 & CNE20 & 0.757 & R2184.c04 & $>20$ \\
\hline Q23.17 & 6.507 & CNE17 & 1.357 & $\mathrm{R} 1166 . \mathrm{c} 01$ & $>20$ \\
\hline Q259.d2.17 & 11.80 & CNE30 & 6.113 & R3265.c06 & $>20$ \\
\hline $0330 . v 4 . c 3$ & 8.322 & CNE52 & 0.508 & C3347.c11 & $>20$ \\
\hline 0260.v5.c36 & 19.80 & CNE53 & 3.008 & C4118.c09 & $>20$ \\
\hline $\mathrm{AC}$ & & $\mathrm{C}$ & & CNE5 & $>20$ \\
\hline 3301.v1.c24 & 1.464 & Du156.12 & 3.729 & CRF01-AG & \\
\hline 6041.v3.c23 & 3.521 & Du172.17 & 1.926 & $\mathrm{~T} 250-4$ & 0.694 \\
\hline 6540.v4.c1 & $>20$ & Du422.1 & 2.904 & $\mathrm{~T} 255-34$ & 0.814 \\
\hline ACD & & ZM197M.PB7 & 0.937 & $\mathrm{~T} 257-31$ & 11.71 \\
\hline 0815.v3.c3 & 0.492 & ZM233M.PB6 & 10.77 & $928-28$ & 16.68 \\
\hline 3103.v3.c10 & 2.763 & ZM249M.PL1 & 0.210 & $263-8$ & 8.705 \\
\hline B & & ZM53M.PB12 & 0.286 & T251-18 & $>20$ \\
\hline 6535.3 & 0.949 & ZM214M.PL15 & 1.876 & T278-50 & 11.46 \\
\hline QH0692.42 & 0.965 & $\mathrm{C}(\mathrm{T} / \mathrm{F})$ & & $\mathrm{D}$ & \\
\hline SC422661.8 & 1.400 & Ce0393_C3 & 0.262 & 3016.v5.c45 & 0.377 \\
\hline PVO.4 & 0.810 & Ce1176_A3 & 2.650 & A07412M1.vrc12 & 0.953 \\
\hline TRO.11 & 3.666 & Ce2010_F5 & 3.621 & 231965.c01 & 3.720 \\
\hline AC10.029 & 1.260 & BF1266.431a & 0.256 & $\mathrm{D}(\mathrm{T} / \mathrm{F})$ & \\
\hline RHPA4259.7 & 3.885 & $\mathrm{CD}$ & & 191821_E6_1 & 0.194 \\
\hline THRO4156.18 & 2.059 & 3817.v2.c59 & 3.484 & $\mathrm{G}$ & \\
\hline $\mathrm{B}(\mathrm{T} / \mathrm{C})$ & & 6952.v1.c20 & 0.734 & X1193_c1 & $>20$ \\
\hline WEAU_d15_410_5017 & 3.584 & 89-F1_2_25 & 0.134 & P0402_c2_11 & $>20$ \\
\hline 1006_11__C3_1601 & 0.885 & 6811.v7.c18 & $>20$ & X1254_c3 & $>20$ \\
\hline 1054_07_TC4_1499 & 1.894 & & & X2088_c9 & $>20$ \\
\hline & & & & X2131_C1_B5 & $>20$ \\
\hline & & & & P1981_C5_3 & 18.45 \\
\hline
\end{tabular}

$\mathrm{T} / \mathrm{F}$, transmitted founders. 
A


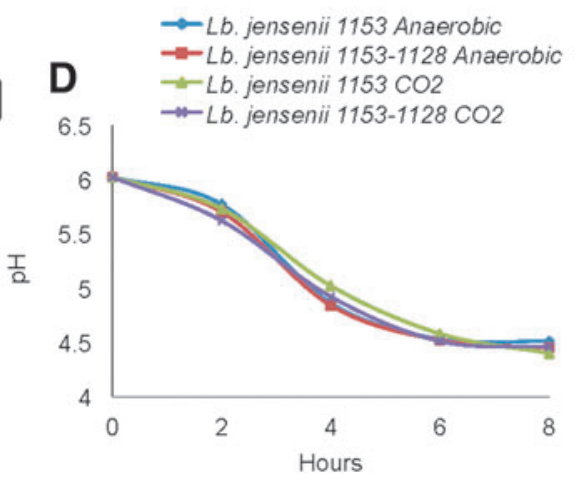

FIG. 4. Construction and characterization of recombinant Lactobacillus. (A) Construction of L. jensenii 1153-1128 was performed by site-specific integration of the p23-AP-m36.4 gene into the minor capsid gene locus in the Lactobacillus chromosome. A diagram of the recombinant construction is shown. (B) PCR fragment length analysis of the parent and recombinants. PCR was carried out using primers within the minor capsid gene and flanking the AP-m36.4 expression cassette $891 \mathrm{bp}$ Int, and with primers external to the minor capsid gene. The parental strain shows a $353 \mathrm{bp}$ fragment when amplified by internal primers and a 1,824 bp fragment when amplified by the Ext primers. Recombinant strain WCB 1128 shows a 1,250 and 2,721 bp fragment, respectively, with the insertion of the 891 cassette plus a 6 bp restriction site. A longterm (40 generation) culture also showed the same PCR fragment length pattern. (C) Growth curves are shown for the parental L. jensenii 1153 strain and recombinant L. jensenii 1153-1128 strain, under anaerobic and $5 \% \mathrm{CO}_{2}$ growth conditions. (D) Lactic acid production as measured by $\mathrm{pH}$ is shown for the parental L. jensenii 1153 strain and recombinant L. jensenii 1153-1128 strain, under anaerobic and 5\% $\mathrm{CO}_{2}$ growth conditions. Ext, external; Int, integration site; PCR, polymerase chain reaction; WCB, working cell bank.

\section{Discussion}

There is a tremendous need for approaches to combat HIV-1 transmission in women of reproductive age. Lactobacilli (including $L$. jensenii) are important members of the vaginal microbiome, lowering vaginal $\mathrm{pH}^{31,32}$ modulating cervicovaginal inflammation, ${ }^{9}$ and providing resistance to HIV infection. ${ }^{33} \mathrm{We}$ established the feasibility of expressing bioactive anti-HIV-1 antibody fragments from a vaginal strain of $L$. jensenii and show that these fragments are functional and can be stably expressed from a recombinant $L$. jensenii. In addition, we confirmed that the recombinant $L$. jensenii $1153-1128$ expressing m36.4 could colonize the rhesus macaque vagina (data not shown).

ScFv-m9 was expressed at lower levels and had lower affinity for FLSC, so it was not pursued. However, the smaller dAbs $\mathrm{m} 36$ and m36.4 could be expressed at high levels and thus were more viable for this approach. It is noteworthy to mention that the small $\mathrm{dAb}$ fragments $\mathrm{m} 36$ and m36.4 can bind the CD4i epitope even without the conformational change that occurs with CD4 binding to gp120.

Previously, several groups have used other commensals to express functional antibody fragments. Early work used the commensal Streptococcus gordonii engineered to produce
$\mathrm{scFv} \mathrm{H} 6$ and an anti-idiotypic scFv with anti-Candida activity. ${ }^{34,35}$ S. gordonii was also used to produce Guy's 13 scFv against the caries-producing bacterium Streptococcus mutans. ${ }^{36}$

Marcotte et al. expressed $\mathrm{scFv}$ on the surface of Lactobacillus paracasei against Porphyromonas gingivalis, ${ }^{37}$ and Kruger et al. used Lactobacillus casei expressing an $\mathrm{scFv}$ against $S$. mutans, ${ }^{38}$ both approaches reduced dental caries. $L$. paracase $i$ was used to express an $\mathrm{scFv}$ to protect against anthrax edema toxin caused by the bacterium Bacillus anthracis. ${ }^{39}$ L. casei, L. paracasei, and Lactobacillus rhamnosus GG were engineered to express llama VHH antibody fragments against rotavirus. ${ }^{40,41}$ Most recently, Andersen et al. described the use of single dAbs to neutralize Clostridium difficile toxin $\mathrm{B}^{42}$

Another noteworthy approach is the use of adenoassociated virus (AAV) to deliver broadly neutralizing antibodies. ${ }^{43}$ While the approach appears to be safe, and the AAV are long lived in the tissue and can secrete antibody persistently, one caveat with this approach is the inability to remove the AAV vector easily, should the need arise. Commensal bacteria (expressing antibodies) can be removed by treatment with an appropriate antibiotic. 
Although the idea of expressing antibody fragments in commensals is not new, with the increasing development of antibiotic and antiviral resistance and therefore fewer treatment options for both bacterial and viral infections, new approaches are needed. With a better appreciation of the health benefits provided by commensals as part of the microbiome, perhaps this is an approach whose time has come.

For prevention of HIV, the benefit to using human colonizing vaginal strains would allow for delivery of antibodies mucosally at the site where the virus first enters the body. Development of broadly neutralizing antibodies in infected individuals, in the blood or at mucosal sites, takes months to years. Current vaccine strategies do not uniformly generate these antibodies. Our results indicate that stable expression of anti-HIV-1 antibody fragments is possible using a common Lactobacillus in the vaginal microbiota as a recombinant live biotherapeutic. m36.4 was used as a prototype antibody fragment, but other newly discovered broadly neutralizing antibodies might also be candidates to test in this approach.

\section{Acknowledgments}

We thank the Michael Seamen Laboratory at Harvard Medical School for performing the TZM-bl pseudovirus assays. This work was funded, in part, by the Bill and Melinda Gates Foundation GCE Phase 1 and 2 OPP1035271 and NIH grant 5R44AI100753-03. This work was supported by the National Institutes of Health, SBIR grant 1R43AI100753-01.

\section{Author Disclosure Statement}

L.A.L., P.P.L., and T.P.P. work for Osel, a biotherapeutics company that is developing $L$. jensenii as a delivery system for anti-HIV therapeutics, and are shareholders. A.M. works for Osel. X.L. and L.J. previously worked for Osel. X.L. is a shareholder of Osel, Inc. A.S.D. and W.Z. declare no conflicts. T.R.F. is a founder and shareholder of Profectus Biosciences, Inc.

\section{References}

1. Wilson NA, Watkins DI: Is an HIV vaccine possible? Braz J Infect Dis 2009;13:304-310.

2. Baba TW, Liska V, Hofmann-Lehmann R, et al.: Human neutralizing monoclonal antibodies of the $\mathrm{IgG1}$ subtype protect against mucosal simian-human immunodeficiency virus infection. Nat Med 2000;6:200-206.

3. Conley AJ, Kessler JA 2nd, Boots LJ, et al:: The consequence of passive administration of an anti-human immunodeficiency virus type 1 neutralizing monoclonal antibody before challenge of chimpanzees with a primary virus isolate. J Virol 1996;70:6751-6758.

4. Foresman L, Jia F, Li Z, et al:: Neutralizing antibodies administered before, but not after, virulent SHIV prevent infection in macaques. AIDS Res Hum Retroviruses 1998; 14:1035-1043.

5. Hessell AJ, Poignard P, Hunter M, et al.: Effective, lowtiter antibody protection against low-dose repeated mucosal SHIV challenge in macaques. Nat Med 2009;15:951-954.

6. Hessell AJ, Rakasz EG, Poignard P, et al.: Broadly neutralizing human anti-HIV antibody $2 \mathrm{G} 12$ is effective in protection against mucosal SHIV challenge even at low serum neutralizing titers. PLoS Pathog 2009;5:e1000433.
7. Antonio MA, Hawes SE, Hillier SL: The identification of vaginal Lactobacillus species and the demographic and microbiologic characteristics of women colonized by these species. J Infect Dis 1999;180:1950-1956.

8. Ravel J, Gajer P, Abdo Z, et al.: Vaginal microbiome of reproductive-age women. Proc Natl Acad Sci U S A 2011; 108(Suppl 1):4680-4687.

9. Anahtar MN, Byrne EH, Doherty KE, et al.: Cervicovaginal bacteria are a major modulator of host inflammatory responses in the female genital tract. Immunity 2015;42:965-976.

10. Lagenaur LA, Sanders-Beer BE, Brichacek B, et al.: Prevention of vaginal SHIV transmission in macaques by a live recombinant Lactobacillus. Mucosal Immunol 2011;4: 648-657.

11. Berger EA, Murphy PM, Farber JM: Chemokine receptors as HIV-1 coreceptors: Roles in viral entry, tropism, and disease. Annu Rev Immunol 1999;17:657-700.

12. Wyatt R, Kwong PD, Desjardins E, et al:: The antigenic structure of the HIV gp120 envelope glycoprotein. Nature 1998;393:705-711.

13. Salzwedel K, Smith ED, Dey B, Berger EA: Sequential CD4-coreceptor interactions in human immunodeficiency virus type 1 Env function: Soluble CD4 activates Env for coreceptor-dependent fusion and reveals blocking activities of antibodies against cryptic conserved epitopes on gp120. J Virol 2000;74:326-333.

14. Xiang SH, Doka N, Choudhary RK, Sodroski J, Robinson JE: Characterization of CD4-induced epitopes on the HIV type 1 gp120 envelope glycoprotein recognized by neutralizing human monoclonal antibodies. AIDS Res Hum Retroviruses 2002;18:1207-1217.

15. Labrijn AF, Poignard P, Raja A, et al.: Access of antibody molecules to the conserved coreceptor binding site on glycoprotein gp120 is sterically restricted on primary human immunodeficiency virus type 1. J Virol 2003;77:10557-10565.

16. Wang HW, Cole D, Jiang WZ, et al:: Engineering and functional evaluation of a single-chain antibody against HIV-1 external glycoprotein gp120. Clin Exp Immunol 2005; 141:72-80.

17. Chancey CJ, Khanna KV, Seegers JF, et al.: Lactobacilliexpressed single-chain variable fragment ( $\mathrm{scFv}$ ) specific for intercellular adhesion molecule 1 (ICAM-1) blocks cellassociated HIV-1 transmission across a cervical epithelial monolayer. J Immunol 2006;176:5627-5636.

18. Forsman A, Beirnaert E, Aasa-Chapman MM, et al.: Llama antibody fragments with cross-subtype human immunodeficiency virus type 1 (HIV-1)-neutralizing properties and high affinity for HIV-1 gp120. J Virol 2008;82:12069-12081.

19. Chen W, Xiao X, Wang Y, Zhu Z, Dimitrov DS: Bifunctional fusion proteins of the human engineered antibody domain m36 with human soluble CD4 are potent inhibitors of diverse HIV-1 isolates. Antiviral Res 2010;88:107-115.

20. Koh WW, Steffensen S, Gonzalez-Pajuelo M, et al.: Generation of a family-specific phage library of llama single chain antibody fragments that neutralize HIV-1. J Biol Chem 2010;285:19116-19124.

21. McCoy LE, Quigley AF, Strokappe NM, et al.: Potent and broad neutralization of HIV-1 by a llama antibody elicited by immunization. J Exp Med 2012;209:1091-1103.

22. Lutje Hulsik D, Liu YY, Strokappe NM, et al.: A gp41 MPER-specific llama VHH requires a hydrophobic CDR3 for neutralization but not for antigen recognition. PLoS Pathog 2013;9:e1003202. 
23. Zhang MY, Shu Y, Rudolph D, et al: Improved breadth and potency of an HIV-1-neutralizing human single-chain antibody by random mutagenesis and sequential antigen panning. J Mol Biol 2004;335:209-219.

24. Zhang MY, Borges AR, Ptak RG, et al.: Potent and broad neutralizing activity of a single chain antibody fragment against cell-free and cell-associated HIV-1. MAbs 2010;2: 266-274.

25. Chen W, Zhu Z, Feng Y, Dimitrov DS: Human domain antibodies to conserved sterically restricted regions on gp120 as exceptionally potent cross-reactive HIV-1 neutralizers. Proc Natl Acad Sci U S A 2008;105:17121-17126.

26. Chen W, Dimitrov DS: Human monoclonal antibodies and engineered antibody domains as HIV-1 entry inhibitors. Curr Opin HIV AIDS 2009;4:112-117.

27. Chang TL, Chang CH, Simpson DA, et al.: Inhibition of HIV infectivity by a natural human isolate of Lactobacillus jensenii engineered to express functional two-domain CD4. Proc Natl Acad Sci U S A 2003;100:11672-11677.

28. Dennis MS, Zhang M, Meng YG, et al.: Albumin binding as a general strategy for improving the pharmacokinetics of proteins. J Biol Chem 2002;277:35035-35043.

29. Montefiori DC: Evaluating Neutralizing Antibodies Against HIV, SIV, and SHIV in Luciferase Reporter Gene Assays. John Wiley \& Sons, Inc., New York, 2004.

30. Liu X, Lagenaur LA, Simpson DA, et al:: Engineered vaginal Lactobacillus strain for mucosal delivery of the human immunodeficiency virus inhibitor cyanovirin-N. Antimicrob Agents Chemother 2006;50:3250-3259.

31. Boskey ER, Cone RA, Whaley KJ, Moench TR: Origins of vaginal acidity: High $\mathrm{D} / \mathrm{L}$ lactate ratio is consistent with bacteria being the primary source. Hum Reprod 2001;16: 1809-1813.

32. Boskey ER, Telsch KM, Whaley KJ, Moench TR, Cone RA: Acid production by vaginal flora in vitro is consistent with the rate and extent of vaginal acidification. Infect Immun 1999;67:5170-5175.

33. Hillier SL: The vaginal microbial ecosystem and resistance to HIV. AIDS Res Hum Retroviruses 1998;14(Suppl 1): S17-S21.

34. Beninati C, Oggioni MR, Boccanera M, et al.: Therapy of mucosal candidiasis by expression of an anti-idiotype in human commensal bacteria. Nat Biotechnol 2000;18:10601064.
35. Oggioni MR, Beninati C, Boccanera M, et al:: Recombinant Streptococcus gordonii for mucosal delivery of a scFv microbicidal antibody. Int Rev Immunol 2001;20: 275-287.

36. Giomarelli B, Maggi T, Younson J, Kelly C, Pozzi G: Expression of a functional single-chain Fv antibody on the surface of Streptococcus gordonii. Mol Biotechnol 2004; 28:105-112.

37. Marcotte H, Koll-Klais P, Hultberg A, et al.: Expression of single-chain antibody against RgpA protease of Porphyromonas gingivalis in Lactobacillus. J Appl Microbiol 2006; 100:256-263.

38. Kruger $\mathrm{C}, \mathrm{Hu} \mathrm{Y}$, Pan Q, et al.: In situ delivery of passive immunity by lactobacilli producing single-chain antibodies. Nat Biotechnol 2002;20:702-706.

39. Andersen KK, Marcotte H, Alvarez B, Boyaka PN, Hammarstrom L: In situ gastrointestinal protection against anthrax edema toxin by single-chain antibody fragment producing lactobacilli. BMC Biotechnol 2011;11:126.

40. Gunaydin G, Alvarez B, Lin Y, Hammarstrom L, Marcotte $\mathrm{H}$ : Co-expression of anti-rotavirus proteins (llama $\mathrm{VHH}$ antibody fragments) in Lactobacillus: Development and functionality of vectors containing two expression cassettes in tandem. PLoS One 2014;9:e96409.

41. Alvarez B, Krogh-Andersen K, Tellgren-Roth C, et al.: An exopolysaccharide-deficient mutant of Lactobacillus rhamnosus GG efficiently displays a protective Llama antibody fragment against rotavirus on its surface. Appl Environ Microbiol 2015;81:5784-5793.

42. Andersen KK, Strokappe NM, Hultberg A, et al:: Neutralization of Clostridium difficile toxin B mediated by engineered lactobacilli producing single domain antibodies. Infect Immun 2015;84:395-406.

43. Schnepp BC, Johnson PR: Adeno-associated virus delivery of broadly neutralizing antibodies. Curr Opin HIV AIDS 2014;9:250-256.

Address correspondence to:

Laurel A. Lagenaur

Osel, Inc.

320 Logue Avenue

Mountain View, CA 94043

E-mail: 1lagenaur@oselinc.com 